\title{
El hombre, ¿un lobo para el hombre? (Racionalidad práctica y alteridad en el pensamiento de Thomas Hobbes)
}

\author{
JOSÉ MANUEL PANEA MÁRQUEZ \\ Universidad de Sevilla
}

RESUMEN

El objeto de este artículo es analizar las relaciones entre Moral y Política en el pensamiento de Hobbes. En nuestra opinión. Hobbes no fue un pesimista antropológico, sino un buen conocedor del hombre y de sus posibilidades. Por ello, fue un decidido defensor de la razón príctica, cuyo conocpto se construye sin perder de vista a los otros, tanto en la acción moral como en la politica. PALABRAS CLAVE

HOBHES-MORAL-POLITICA-RAZON PRACTICA

ABSTRACT

The aim of this paper is to examine the relation between morals and politics in the thought of Thomas Hobbes. My point is that Hoobes was not an anthropological pessimist, but a deep thinker of man and his possibilities. Therefore, he was a determined defender of practical reason. the concept of which is based upon the experience of human interaction, both moral and political. KEYWORDS

HOBBES-MORALS-POLITICS-PRACTICAL. REASON

\begin{abstract}
*La razón no es menos natural en el hombre que la pasión, y es la misma para todos los hombres, porque todos los hombres están de acuerdo en su voluntad de regirse y gobernarse de suerte que alcancen sus descos, es decir, su propio bien, lo cual es obra de la razón»l.
\end{abstract}

1 De Corpore Politico, or the Elements of Law, en The English Works of Thomas Hobbes, 4. p. 87. Elementos de Derecho Natural y Politico, trad. de Dalmacio Negro Pavón. Madrid:

(6) Contrasies. Revista Interdisciplinar de Filosofia, vol. IV (1999), pp, 97-111. ISSN: 1136-4076 Sección de Filosofia, Universidad de Málaga. Facultad de Filosofla y Letras

Compus de Teatinos, E-2907i Málaga (Espeña) 
«Y la razón sugiere convenientes normas de paz.

basándose en las cuales los hombres pueden llegar a un acuerdo»2.

\section{EL HOMBRE: ENTRE LA RAZÓN Y LA PASIÓN}

El pensamiento de Thomas Hobbes. ${ }^{3}$ es todo menos plano; y fue siempre nuestro pensador un filósofo con los pies bien en el suelo. La reflexión desde el estudio y la experiencia de la realidad humana será el punto de partida para toda su ulterior indagación $n^{4}$. No es de extrañar, pues, que si echamos un vistazo al índice de su obra más total, a saber, Leviathan, dedique la primera parte al estudio del Hombre. Y es que nuestro autor, pese a que esto haya sido puesto en duda, es un pensador sistemático y unitario 5 . Hobbes, cuya vocación por la filosofía política nadie tendría la osadía de cuestionar, nos ha dejado una obra teórica importante en la que siempre tendrá como referente lo que fue su punto de partida: la humana condición.

Y Hobbes conocía muy bien los pliegues de la subjetividad humana, con todas sus complejidades y tensiones. Su visión integral del Hombre es la prueba más palpable de que era plenamente consciente de ese forcejeo entre la razón y la pasión que a todos nos atañe 6 . Sin negar o pretender ignorar la diver-

Centro de Estudios Constitucionales, 1979. Parte I, XV.1. p. 210]. Todas las citas de Hobbes las haremos teniendo en cuenta, en primer lugar. la edición de Molesworth (The English Works of Thomas Hobbes. EW, Scientia Verlag Aalen. 1966) y, en segundo lugar, entre corchetes. la edjción castellana, por ser ésta la que citemos en el texto. Para el De Cive citaremos sólo por la edición bilinguie a cargo de J. Rodríguez Feo ITh. Hobbes, El ciudadano. Madrid: Debate-CSIC, 1993], realizada sobre la edición crítica de Howard Warrender.

2 Th. Hobbes, Leviathan. XIII, p. 116. |Leviatán. Madrid: Alianza Universidad, trad, de Carlos Mellizo, 1989, p. 109].

3 Para una amplia y detallada información sobre su vida y obra, cf. F. Tönnies. Hobbes. vida y doctrina. Madrid: Alianza Universidad. 1988.

4 Un interesante desarrollo de esta tesis lo encontramos en L. Strauss. The Political Philosophy of Hobbes. Its Basis and its Genesis. Chicago: University Press, 1963.

5 Cf. en este respecto el clásico trabajo de J. Watkins, Hobbes, system of ideas. London: Hutchinson, 1956. [Qué ha dicho verdaderamente Hobbes. Madrid: Doncel, 1972]. En este sentido, compartimos con J. Rodríguez Feo la tesis de que «No hay una formulación por parte de Hobbes de una Filosofía Moral separada de su Filosofía Política»: J. Rodriguez Feo, «Introducción» a Th. Hobbes, El ciudadano, p. XXXVII.

6 Pero las pasiones que conducen a la insociabilidad pierden la batalla contra las pasiones que anhelan paz y seguridad, siendo en favor de éstas para quien la razón va a ponerse a trabajar y a encontrar los preceptos que nos han de conducir a aquélla. Por todo ello escribirá Hobbes: «Y hasta aquí. lo que se refiere a la mala condición en la que está el hombre en su desnuda 
sidad cultural, la pluralidad de creencias y opiniones, de la que fue buen testigo, creía, a pesar de todo, que hay una estructura natural común a todos los hombres, sin distinción de sexo, raza ni condición social; dicho de otro modo, creía que, a pesar de que los hombres interpretamos el mundo de modos diversos, aún puede hablarse de una común naturaleza humana ${ }^{7}$ y, de alguna manera, de un mundo compartido. Pues bien, de esa naturaleza humana común emergen las pasiones, y su contrapunto, la razón, en ese universo no plano, en ese campo de fuerzas que es la realidad para Hobbes. Odiamos, amamos, tememos, esperamos, sabemos, ignoramos, y así podríamos continuar una larga lista de lucha de contrarios. Pero, en definitiva, no otra cosa es el Hombre para Hobbes sino un tenso abrazo entre la pasión y la razón. Los contrarios recorren el pensamiento hobbesiano porque, sencillamente, entretejen la vida que vivimos, y nuestro filósofo quiere hacerse plenamente cargo de ella. Los pares vida- muerte, esperanza-miedo, guerra-paz, son buena prueba de la tensión que encierra cualquier aspecto de la realidad a poco que, de la mano de Hobbes, reflexionemos sobre ella.

Con frecuencia se habla de que Hobbes es un pesimista antropológico, pesimismo que va más allá de no confiar en las posibilidades racionales del ser humano para otorgarle incluso una gran dosis de maldad. Pero ni es esa la opinión que Hobbes guardaba de sus semejantes ${ }^{8}$, ni tampoco es la que guardamos nosotros de Hobbes. Nuestro filósofo conocía bien los pliegues de la humana condición, sabía de sus miserias, pero también, y apostó decididamente por ello, de su mayor grandeza: la razón; no tenía, desde luego, una idea angélica del ser humano, pues algo así no lo resistiría la más superficial introspección, ni el más leve contacto con la experiencia, pero conocía también esa otra posibilidad constructiva que todo hombre encierra: su razonabilidad, es decir, la posibilidad, siempre a punto de irse a pique, de optar por la razón.

naturaleza, si bien tiene una posibilidad de salir de ese estado, posibilidad que, en parte, radica en sus pasiones, y, en parte, en su razón. Las pasiones que inclinan a los hombres a buscar la paz son el miedo a la muerte, el deseo de obtener las cosas para vivir cómodamente, y la esperanza de que, en su trabajo, puedan conseguirlas. Y la razón sugiere convenientes mormas de paz, basándose en las cuales los hombres pueden liegar a un acuerdom. Leviathan, XIII, pp. 115-116, [p. 109].

7 Ibid., p. 110, [p. 105].

8 Sin un poder común que los reprima, nos dice Hobbes, los hombres tenderán no ya a dañarse unos a otros, pero sí a desconfiar mutuamente. Pero de esto no puede seguirse la tesis de la maldad humana: «Pero que los hombres sean malos por naturaleza no se sigue de mi principio.» De Cive, p. 8. Y en Leviathan vuelve a insistir Hobbes sobre la desconfianza mutua, pero este temor mutuo, esta experiencia de inseguridad frente al otro no implica que estemos acusando con ello a la naturaleza humana, pues los deseos y otras pasiones humanas no son, nos dice Hobbes, un pecado en sí mismo. Leviathan, XIII, p. 114. [p. 108]. 
Pues bien, como no tenía una idea angélica del Hombre, fue bien pronto consciente de la inestabilidad y del poder de las pasiones, así como de su facilidad para entrar en conflicto con las de los otros ${ }^{9}$. Conocía, pues, esa parte oscura de nuestra humanidad, alimentada por el instinto de la más primitiva y salvaje autoconservación; pero también creía en la posibilidad de dar una salida humana a tal inaplazable exigencia. Y la única respuesta al problema de cómo resolver los conflictos que la dinámica de la ciega autoconservación pone en marcha es la que proviene de la razón.

Porque, como veremos, si la razón, en una de sus facetas, tiene que ver con el cálculo, no se agotan aquí sus competencias. La razón, nos ha dicho Hobbes, no es menos natural en el hombre que la pasión, y nos sugiere convenientes normas de paz, basándose en las cuales los hombres pueden llegar a un acuerdo. Dicho de otro modo, Hobbes cree en la racionalidad como en una posibilidad humana que es capaz de sugerirnos pautas de actuación cuando se le pregunta cómo salir de ese violento y caótico atolladero en que están las enfrentadas subjetividades sin freno; pautas que, en definitiva, nos trasladan del ciego escenario natural de la autoconservación sin límite al escenario de la moral, aunque, con toda probabilidad, necesitado de auxilio y protección.

\section{Razón y autoconservación: De la Moral. a la Politica}

Como apuntábamos más arriba, lo que entiende Hobbes por razón no es sólo una facultad que realiza operaciones lógicas sin más. Para Hobbes, la razón está anclada en nuestra estructura biológica, que, podríamos decirlo así, piensa en clave de autoconservación ${ }^{10}$. En otras palabras, la razón, tal y como Hobbes

9 A diferencia de las abejas y las hormigas, apunta Hobbes, «los hombres están compitiendo continuamente por el honor y la dignidad, cosa que no hacen estas criaturas. Como consecuencia, surge entre los hombres, por esa razón. envidia y odio, y, en última instancia, la guerra»: ibid., XVII, p. 156, [p. 143].

10 En De Cive 1, 7, p. 18, leemos: «Así pues, entre tantos peligros, el precaverse de las amenazas que a diario acechan a todos por la codicia natural de los hombres no es en absoluto censurable, porque no podemos obrar de otro modo. Todos se ven arrastrados a desear lo que es bueno para ellos y a huir de lo que es malo, sobre todo del mayor de los males naturales que es la muerte; $y$ ello por una necesidad natural no menor que la que lleva la piedra hacia abajo. Por consiguiente, nada tiene de absurdo, ni de reprensible. ni de contrario a la recta razón, el que alguien dedique todo su esfuerzo a defender su propio cuerpo y sus miembros de la muerte y del dolor, y a conservarlom. Por eso dirá Hobbes más adelante, en el capítulo II, 1, p. 23: «Pues es la ley una cierta recta razón que al formar parte de la naturaleza humana, no menos que cualquier otra facultad o afección del ánimo, se llama también natural. Es pues la ley natural, por definirla ya, un dictamen de la recta razón acerca de lo que se ha de hacer u omitir para la conservación. a ser posible duradera, de la vida y de los miembros». 
la entiende, no es un artefacto ajeno, separado del cuerpo y de sus funciones, sino que forma una unidad tal que estará al servicio de la protección de la vida humana y de la integridad física. Por ello, para Hobbes, razón y autoconservación van una junto a la otra, pues resultará ser racional aquella conducta que esté orientada a aquel fin, es decir, que nos garantice la protección de nuestra propia vida. Así pues, la afirmación de Hobbes de que la razón no es menos natural en el hombre que la pasión nos parece decisiva. Para Hobbes, preguntar si hacer A es más racional que hacer B no tiene otra forma de averiguarse sino indagando qué alternativa favorece mejor la autoconservación. La vida humana, en tanto naturaleza, quiere perpetuarse en el ser, quiere la satisfacción de sus necesidades, y la razón, en tanto que es parte de esa naturaleza, se pone a trabajar para ponerla a salvo, así como para promover la satisfacción de aquellas necesidades, que son el soporte de la vida.

Lo que ocurre es que para Hobbes también cabe hablar de una autoconservación insensata, estúpida, que confía ingenuamente en sus propias fuerzas (ignorando que hasta el más débil de los hombres, por decirlo así, puede acabar con el más fuerte) y que se entrega, presa del individualismo más encarnizado, a una despiadada e insoportable guerra de todos contra todos, guerra que más tarde o más temprano tendrá que acabar abriendo paso a esa otra autoconservación inteligente, racional, donde la felicidad y paz social puedan estar garantizadas.

Por eso, nos dirá Hobbes, el que no terminemos despedazándonos los unos a los otros dependerá, en gran medida, de que acatemos o no los dictados de la razón, es decir, de que orientemos nuestra conducta atendiendo a esas pautas normativas posibilitadoras de la paz. Y como la razón no es en el hombre menos natural que la pasión, sigue llamando Hobbes a estos dictados, quizás no con mucho acierto, según él mismo nos confiesa, «leyes de naturaleza» 11 . Si lo preferimos, por decirlo en una expresión que nos es más cercana, la posibilidad de que no convirtamos nuestro entorno humano en una explosión de barbarie radicará en que precisamente respetemos esas «convenientes normas de paz, basándose en las cuales los hombres pueden llegar a un acuerdo»12.

11 «Los hombres han solido dar el nombre de leyes a estos dictados de la razón. pero lo han hecho impropiamente\%. Leviathan, XV, p. 147, [p. 133].

12 Por eso, como muy bien ha visto Kavka, las leyes de naturaleza (laws of nature) son dictados de la razón que tienen que ver con la conducta interpersonal. Cf. G. S. Kavka, Hobbesian Moral and Political Theory. Princeton: Princeton University Press. 1986, p. 342. El derecho natural (the right of nature), volcado en la ciega autoconservación, no implica adoptar una actitud racional (cf. ibid.). Por ello, apunta Kavka, el complejo vínculo entre los derechos naturales y las leyes de naturaleza es posible gracias a la mediación del concepto de recta razón (right reason) ( $c f$. p. 338 ), pero las leyes de naturaleza, en tanto principios de carácter moral (moral ought-principles, general moral prescriptions), vinculados a la recta razón, no son fruto ni de mandato alguno, ni de consentimiento ( $c f$. p. 341 ). 
Para nuestro autor, la razón está, decididamente, al servicio de la vida, y si nos preguntamos qué debemos hacer contestará que lo más natural y racional será obrar de tal modo que no pongamos a aquélla en peligro. Por eso, cuando pedimos a la razón que nos dicte qué hacer para salvaguardar la vida, las conclusiones (conclusions) ${ }^{13}$ a las que la razón llega para garantizar la autoconservación serán, propiamente hablando, dictados racionales; éstos, por consiguiente, no son meros «mandatos» biológicos, ni jurídicos, sino que proceden de nuestra racionalidad práctica que ha reflexionado sobre el modo de preservar la vida, y, por ello, Hobbes los llama también virtudes morales (moral virtues) 14 , pues constituyen la fortaleza más inteligente para garantizar la paz y hacer posible el desarrollo de nuestra propia vidals.

En este sentido, tal y como a nosotros nos parece ${ }^{16}$, los mandatos racionales imponen deberes, cuyo cumplimiento será obligatorio para nosotros sólo si queremos preservar la vida de un modo inteligente o, dicho de otro modo, sólo si de veras queremos ser racionales; es decir, mandan

13 Leviathan, XV. p. 147, [p. 133]. También las llama Hobbes «hábitos mentales»(habits of the mind ) conducentes a la paz. Leviathan, XXVI, p. 271, [p. 229].

14 Ibid., p. 146, [p. 133].

15 Pero lo interesante es subrayar que también, como hemos visto ya, la posibilidad de salir del bárbaro estado de naturaleza lo encontramos tanto en las pasiones (que anhelan la paz). como en la razón, que nos dictan las normas para, a través del acuerdo, alcanzar la paz. Cf. ibid., XIII, p. 116, [p. 109].

16 Mucho se ha discutido sobre el carácter de la ley de naturaleza en Hobbes. Así, por referimos a alguna de las opiniones que al respecto se han vertido, cabría destacar las siguientes: la célebre tesis Taylor-Warrender sostiene que las leyes de naturaleza no son meros consejos sobre la prudente búsqueda del interés propio, sino leyes morales que imponen deberes; son mandatos de Dios, y, por tanto, constituyen una deontología muy estricta. Cf. A. E. Taylor. "The Ethical Doctrine of Hobbes», Philosophy, (1938), en K. C. Brown, (ed.), Hobbes Sudies. Oxford: Basil Blackwell, 1965, pp. 35-55; H. Warrender, The Political Philosophy of Hobbes: His Theory of Obligation. Oxford: Clarendon Press, 1957. Para Watkins, las leyes de naturaleza se asemejarían a las prescripciones del médico en aras de la salud (J. Watkins, op. cit). Según Oakeshott, Hobbes distingue lo que es una conducta racional de lo que es una conducta obligatoria, y las leyes de naturaleza son de carácter racional, pero no obligatorio (M. Oakeshott. Hobbes, on Civil Association. Oxford: Basil-Blackwell, 1975, pp. 90, 103, 114, 119). Para Bobbio, la ley de naturaleza. de carácter prudencial, no obliga en absoluto al soberano, hasta el punto de ser un mero flatus vocis (N. Bobbio, Thomas Hobbes. Barcelona: Paradigma, 1990, p. 195). Lco Strauss cree que la ley natural hobbesiana no es sino una deducción del principio fundamental de la autoconservación (L. Strauss, op. cir, pp. 159-160). Por último queremos expresar nuestra afinidad con la tesis de Gauthier, para quien las leyes de naturaleza no son mandatos, como piensa Taylor, sino consejos o requerimientos de la recta razón. D. Gauthier. The Logic of Leviathan. The Moral and Political Theory of Thomas Hobbes. Oxford. Clarendon Press, $1^{2}$ reimp. 1979, pp. 47-50, 66-76. Consejos, diríamos nosotros, para no salirnos fuera de la órbita de la racionalidad. 
hipotéticamente ${ }^{17}$, y lo hacen del mismo modo que cuando decimos que debemos acatar las prescripciones o recomendaciones médicas, si es que queremos seriamente velar por nuestra salud.

Por ello, estos dictados racionales no están inscritos en ningún cielo metafísico (aunque Hobbes los llame también mandatos de Dios, ya que Dios, según nuestro filósofo, es el autor de la Naturaleza, y emergen del deseo natural de preservar la vida), sino que son las conclusiones a las que llega nuestra razón natural (una razón, insistamos en ello, anclada en el deseo de preservar la vida del cuerpo que la encarna) cuando se le pregunta qué debemos hacer para poner a salvo una existencia libre de toda amenaza. Así, si echamos un vistazo a la lista de tales leyes de naturaleza no nos soprenderá encontrar entre ellas, a título de ejemplo, las siguientes: buscar la paz, no hacer uso del derecho a todo, cumplir los convenios, gratitud, complacencia, sociabilidad, perdón, modestia, equidad, humanidad, misericordia, etc. ${ }^{18}$,

Ahora bien, si la solución racional que Hobbes va a encontrar al conflicto de las subjetividades enfrentadas pasa por la moral, otro tanto va a acontecer con la política, que habrá de acudir en su auxilio. Porque, pensará Hobbes, una salida estrictamente moral, apelando a las leyes de naturaleza, a los dictados de la razón, o, dicho de otro modo, apelando sólo al cultivo de las virtudes morales, es una solución muy hermosa, pero que, por sí sola, tardará muy poco en desplomarse en la práctica, pues no siempre somos tan inteligentes o queremos o podemos serlo: tal es es huracán de la pasión.

Y aquí es donde ha de entrar en juego la política, y con ella, la inaplazable y necesaria figura del Estado, un Estado, eso sí, que tendrá que satisfacer como requisito inexcusable de legitimidad la condición de racionalidad, lo cual significará que también el Soberano (individuo o asamblea), único detentador del poder, tendrá delimitado el campo de su actuación legítima por el espacio que los dictados racionales fijan.

De no ceñirse al horizonte de racionalidad que los dictados racionales dibujan, tal Estado sería, sencillamente, irracional, y las fracturas en su legitimidad serían más que evidentes. Porque un poder político que se hubiera edificado al margen de las demandas de racionalidad política no habría vencido ese terror pánico ${ }^{19}$ que azotaba al hombre en el hipotético estado de naturale-

17 Pero este carácter hipotético de la ley natural hobbesiana, sujeta a la condición de que queramos entrar en el discurso de la racionalidad frente a la barbaric, no debe empañar el carácter innegociable. y. en este sentido, eterno, que tienen tales leyes, pues, como Hobbes nos recuerda, la injusticia. la ingratitud. la injuria, la inhumanidad. nunca pueden legitimarse. $C f$. De Cive. III, 29, p. 41.

18 Cf. Leviathan, XIV, XV., y De Cive, III, 31, pp. 41-42.

19 Como muy bien supo ver el Profesor Tierno Galván. la filosofía política de Hobbes quiere hacer frente al miedo político, y por esta razón. el Estado «tiene que cuidar de sus 
za, más aún, sería una amenaza todavía más terrible, pues habría sido fríamente calculado para no dejar un resquicio que escapara a su dominio. La alternativa racional que Hobbes propone, para no dejarnos dominar por el torbellino de las pasiones, es, pues, una solución moral y política a un tiempo20.

Precisamente por eso, se comete un craso error si se concibe la razón hobbesiana como un formal y vacío estuche, en el que pudiera caber cualquier cosa, y cuya única virtualidad fuera el frío cálculo. La razón hobbesiana bien es cierto que es calculadora, lo cual significa que no es ingenua, ni desinteresa$\mathrm{da}$, que atiende a las consecuencias, que se pertrecha bien de los pros y contras de aquello que va a poner por obra. Pero esta calculabilidad, este sopesar se hace, como hemos apuntado ya, sobre un telón de fondo que es el fundamental y que se constituye en el sumum bonum hobbesiano: la vida ${ }^{21}$, cuyos únicos aliados son la razón y la paz.

Por todo ello, si racional es aquello que hacemos para proteger la vida, y si pensamos, si reflexionamos sobre qué conductas, qué reglas y normas tendríamos que seguir para conseguir la defensa de aquélla, no nos extrañará que Hobbes descarte muy pronto el salvaje e insensato 22 "sálvese quien pueda», y

súbditos, no producir en ellos un terror pánico que retrotraería las cosas al estado de naturaleza, es decir, al estado previo al acuerdo o pacto y a la guerra de todos contra todos». Y más adelante apunta algo que nos parece fundamental: «Críticos e historiadores han confundido la posesión absoluta del poder con el ejercicio absoluto del poder. En uno u otro contexto el valor de la expresión *absoluto cambia. En el primer caso posee connotaciones metafísicas y quiere decir que no tiene superior en su orden; en el segundo posee connotaciones específicamente políticas y administrativas y quiere decir que impide, arbitrariamente, la participación de los ciudadanos en la formación y aplicación de las leyes». E. Tiemo Galván, «Estudio Preliminarn a Th. Hobbes, Del ciudadano y Leviatán. Madrid: Tecnos, $2^{a}$ ed., 1991, pp. XI, XIII, XIV. Hobbes no era partidario de dividir el poder, pero sí de limitarlo a los dictados de la razón. Cf. De Cive, VII, nota I, p. 70. Cf. también ibid., VI, 13. nota 3, pp. 60-61.

20 Nos sumamos aqui a la lectura integradora de lo moral y de lo político que hace Badillo O'Farrell del pensamiento de Hobbes, cuando, entre otras cosas, nos recuerda cómo Hobbes aha tenido que soportar durante este larguísimo tiempo, y movido por determinados frentes de propaganda, el 'lastre' de pensador que vivía de espaldas a la moral»: P. Badillo O'Farrell. Fundamentos de Filosofía Política. Madrid: Tecnos, 1998, p. 91.

21 Así lo ha destacado también Norberto Bobbio en op. cit. p. 53.

22 Resultan ilustrativas en este respecto las interesantes palabras de Hobbes cuando dice: «El insensato se dice en su corazón que no existe tal cosa como la justicia; y a veces lo dice también con su lengua. $\mathrm{Y}$ alega, con toda seriedad, que, como la conscrvación y felicidad de cada hombre está encomendada al cuidado que cada cual tiene de sí mismo, no puede haber razón que impida a cada uno hacer todo lo que crea que pueda conducirlo a alcanzar esos fines. $\mathrm{Y}$ así, hacer o no hacer convenios, cumplirlos o no cumplirlos, no es proceder contra razón, si ello redunda en bencficio propio. El insensato no niega, ciertamente, que haya convenios. [...]: pero se hace todavía cuestión de si la injusticia $[. .$.$\rfloor no podrá a veces ser compatible con esa$ razón que dicta a cada uno buscar su propio bien [...]. En consecuencia, el que quebranta un 
que establezca como teoremas racionales, como conclusiones o dictados de la razón, esas impropiamente llamadas leyes de naturaleza, cuya validez práctica depende tan sólo de que queramos optar o no por una vida racional.

Por ello, la moral hobbesiana es hipotética, pues no hay una obligación categórica previa de hacer nada; tan sólo partimos del deseo de vivir y del temor a perder la vida. Y es cuando reflexionamos sobre el modo de ponerla a salvo cuando llegamos a la conclusión de que si queremos con seriedad preservarla, hemos de conducirnos como nos dicta la razón, es decir, no perder de vista, como diría Hobbes, esas convenientes normas de paz basándose en las cuales los hombres pueden llegar a un acuerdo. Así las cosas, las leyes de naturaleza encarnarían la posibilidad humana de salir de una situación que, de llegar a producirse, tarde o temprano se hará insostenible. Y por ello las Ilama Hobbes convenientes normas de paz.

Pero que los hombres puedan traspasar la barrera del daño mutuo y que puedan alcanzar acuerdos dice mucho de la confianza hobbesiana en la racionalidad humana. Ahora bien, esta confianza en el potencial racional del ser humano no es ni ciega ni ingenua. Por ello, y sin abandonarla, acude Hobbes a por refuerzos. La compleja convivencia necesita del poder político. Las leyes de naturaleza, que obligan siempre in foro interno, no obligan in foro externo cuando nuestra vida corre peligro, es decir, cuando los otros (o algunos) no han querido elegir la opción más racional y, entonces, nuestra vida sigue estando amenazada 23 .

Resulta lógico pensar así, pues para Hobbes, ya lo hemos dicho, la razonabilidad de una conducta se mide en términos de su capacidad para salvaguardar y hacer mejorable las condiciones materiales de la vida. No tendría ningún sentido, sería una insensatez por nuestra parte, pretender predicar en el desierto, obrar de acuerdo con los dictados de razón, de acuerdo con las virtudes morales, en un universo de lobos potenciales. Mejor será, nos dice Hobbes, que tomemos conciencia de la necesidad de un Soberano (sea un hombre, sea

pacto o convenio y declara que piensa que puede hacer eso conforme a razón, no puede ser aceptado en el seno de ninguna sociedad que se una para que los hombres encuentren en ella paz y protección. [...] Pero un hombre no puede razonablemente basar su seguridad en estos errores de los demás; $y$, por tanto, si se le deja fuera o es expulsado de la sociedad, perecerá; y si vive en sociedad es sólo por equivocación de los otros, cosa que él no podría prever ni calcular, lo cual implica que él ha actuado contra razón, es decir. contra su propia preservación. [...] Por tanto, la justicia, es decir, la conformidad con lo que se ha convenido o pactado, es una norma de razón que nos prohíbe hacer cualquier cosa que sea destructiva para nuestra vida, y es también, como consecuencia, una ley de naturaleza». Leviathan, XV, pp. 132-134, [pp. 122124].

23 Ibid., XV, pp. 145-146, [p. 132]. 
una asamblea), es decir, de un poder político que mantenga a raya los excesos de la pasión 24 .

\author{
III. DE LA POLÍtica a LA MORAL
}

Pero ¿significa esta inmersión en el universo político un abandono de esa puerta hacia la racionalidad moral que encarnaban las leyes de naturaleza, los dictados racionales, las virtudes morales? En modo alguno, pues no se entendería la necesidad ni la legitimidad de un Estado que no fuera lo suficientemente racional como para poner a salvo aquello que en el mero estado de naturaleza estaba en peligro. Y no es otro el motivo por el que Hobbes no se va a cansar de repetir que la ley positiva, que como tal es la única ley jurídicamente hablando 25 , tiene que desenvolverse en el marco, o, por decirlo de otro modo, tiene que desarrollarse en plena armonía con la ley de naturaleza26; en definitiva, dicho en los términos en que Hobbes lo entiende, la ley positiva tiene que ser coherente con los dictados de razón, pues, por rigurosa definición, si no llegara a satisfacer las demandas de la racionalidad, la ley positiva no podría llamarse

24 Por eso dirá Hobbes: «Si pudiéramos suponer una gran multitud de hombres capaces de regirse mediante la observancia de la justicia y de otras leyes de la naturaleza. sin necesidad de un poder común que los mantuviese atemorizados, podriamos, asi mismo suponer que la humanidad entera sería también capaz de hacerlo. Y, en ese caso, ni el gobierno civil, ni el Estado serían necesarios en absoluto, ya que habría paz sin necesidad de tener que recurrir al sometimientom. Ibid., XVII, p. 155, [p. 143]. Cf. también. De Cive, 1, 2, [pp. 14-17].

Resulta de interés traer aquí la opinión de I. Berlin al respecto: «Pero Hobbes no dice que todas las leyes tengan que ser duras. Esto es un error. Aunque se lo haya interpretado así. Hobbes no quería ni crueldades ni opresión. Lo que quería eran leyes rigurosas, pero sólo lo absolutamente imprescindibles para mantener el orden público.» I. Berlin, Isaiah Berlin en diálogo con Ramin Jahanbegloo. Madrid: Anaya \& Mario Muchnik, 1993, p. 90. Creemos, no obstante, que el papel de la ley en Hobbes va más allá del mero garantizar el orden, alcanzando a las condiciones de desarrollo material $\sin$ las que difícilmente es posible la paz.

25 Cf. De Cive, XIV, 5, p. 125.

26 «La ley natural y la ley civil están contenidas la una en la otra, y tienen igual extensión.» Leviathan, XXVI, p. 253, [p. 217]. Y más adelante nos dice: "Concluyo, por tanto, que en todas las cosas que no son contrarias a la ley moral, es decir, a la ley de naturaleza, todos los súbditos están obligados a obedecer como ley divina lo que las leyes del Estado declaren como tal. Lo cual es evidente para la razón de todo hombre; pues cualquier cosa que no va contra la ley de naturaleza, puede hacerse ley en nombre de quienes tienen el poder soberanow: Ibid., p. 275. [p. 232]. Y en lo que respecta al soberano apunta Hobbes lo siguiente: «Es verdad que todos los soberanos están sujetos a las leyes de naturaleza, pues dichas leyes son divinas y no pueden ser derogadas por ningún hombre ni por ningún Estadon: Ibid., XXIX, p. 312. [pp. 259-260]. No compartimos, la tesis de Bobbio según la cual para Hobbes, «una vez erigido el Estado, las leyes naturales no tienen razón de sen: $\mathrm{N}$. Bobbio, op. cit., p. 177. 
racional, y, entonces, no habríamos avanzado ni un solo palmo en lo que respecta al abandono del selvático estado de naturaleza y su guerra de todos contra todos.

Pero Hobbes es aún más sorprendente, pues su concepto de racionalidad moral y política no se entiende sin el concepto de alteridad. El otro forma parte inexcusable de toda operación -acción que se tilde de racional. Ir por libre es una total insensatez (y a la larga, un peligro amenazador). Racionalidad y alteridad son tan indesligables en el pensamiento moral y político de Hobbes que las leyes de naturaleza, o las conclusiones a las que la razón llega cuando quiere preservar y mejorar la vida, son la condición de posibilidad misma para que el consenso sea alcanzable. Así las cosas, las hobbesianas leyes de naturaleza serían el a priori de una posible comunidad de diálogo. ¿Cómo vamos a alcanzar algún acuerdo, dirá Hobbes, si no nos situamos en el horizonte de racionalidad que las leyes de naturaleza encarnan? $\mathrm{O}$ dicho de otro modo, ¿cómo vamos a alcanzar un acuerdo si previamente no respetamos el marco de racionalidad en el que éste puede ser posible?

\section{EL OTRO: INGREDIENTE ESENCIAL DE LA RAZÓN PRÁCTICA}

Pero el pensamiento de Hobbes se nos muestra aún más interesante, ya que estos dictados racionales, estas conclusiones de la razón que todos hemos de asumir, si es que hemos optado finalmente por ella, son fácilmente comprensibles hasta para la inteligencia menos cultivada, pues vienen a resumirse en el antiguo y bien conocido dicho: no hagas a otro lo que no quisieras que te hicieran a $t^{27}$. $\mathrm{Y}$ bien, lo interesante, a nuestro juicio, no es la cita en cuestión, harto conocida por todos nosotros, sino el que ella sea la mejor síntesis de lo que para Hobbes es la racionalidad práctica. Y este es el dato importante. Porque, como decíamos, para Hobbes no tiene sentido ser racional

27 Nos referimos a este interesante texto: «Tal vez diga alguno, al ver que los anteriores preceptos naturales derivan con un cierto artificio del único dictamen de la razón: el que nos exhorta a nuestra conservación e incolumidad, que la deducción de estas leyes es tan difícil que no cabe esperar que el vulgo las vaya a conocer ni que, en consecuencia, le obliguen. A lo cual respondo que es verdad que la esperanza, el miedo, la ira, la ambición, la avaricia, la vanagloria y demás perturbaciones del espíritu impiden que se puedan conocer las leyes naturales mientras estas pasiones prevalecen. Pero todos, alguna vez, se encuentran con el ánimo tranquilo. $Y$ en esos momentos nada es más fácil de conocer, incluso para el rudo y sin letras, que la ley natural; mediante esta sola regla: que cuando dude de si lo que va a hacer está de acuerdo con el derecho natural o no, se ponga en su lugar. En ese mismo instante aquellas perturbaciones que le instigaban a hacerlo, como si se hubieran pasado al otro platillo de la balanza, le disuadirán de lo mismo. Y esta regla no sólo es fácil, sino que ya desde antiguo se viene celebrando con estas palabras: no hagas a otro lo que no quieras que te hagan a tim. De Cive, III, 26, pp. 39-40. 
al modo formal, computacional, o como quiera llamársele, sino que la racionalidad, en la medida en que la razón es naturaleza, y en la medida en que llamamos racional a la defensa de la vida, se mide con una unidad muy sencilla: el comportamiento empático, el no querer para los otros lo que tampoco querríamos para nosotros. Este «ponernos en la piel del otro» es el criterio fundamental para dilucidar la racionalidad de nuestra conducta, es decir, para saber si estamos teniendo o no un comportamiento moral. Y esto nos parece decisivo, tanto en el ámbito existencial-privado, como en el ámbito público.

Como puede apreciarse, el otro, (aunque sólo sea por el motivo egoísta de que yo también soy un otro para el otro) no es (puede ser) sólo un lobo para el hombre, no es (puede ser) ese infierno, esa fuente permanente de temor: el otro también puede encarnar la esperanza de alcanzar acuerdos, y ser, igualmente, destinatario de un trato no bestial o salvaje, sino racional, humano.

Pero como decíamos, además de esta apelación a la racionalidad en el ámbito privado, existencial, Hobbes hace, coherentemente con su visión antropológica (en esta tensión a la que nos venimos refiriendo), una llamada a la racionalidad del poder, pues de otro modo no prodría justificarse su presencia en la vida humana. Que el poder sea racional exige del Soberano, única fuente de la ley, que sus leyes positivas se desarrollen en el marco de la ley natural, lo que en sus propios términos significa que a la ley positiva no le está permitido ser irracional28.

¿Es que el pensamiento político de Hobbes posibilita otra cosa? ¿Es que el Soberano de Hobbes, sea un hombre, sea una asamblea, puede ser un lobo para el Hombre dentro de su esquema teórico? Con toda rotundidad, no. Resulta una contradicción pensar que el Soberano no atendiera a las demandas de racionalidad que la legitimación del poder reclama, porque si esto no ocurriera, nos dice Hobbes, se pondría en peligro la seguridad y el bienestar del pueblo que son el fundamento mismo de la necesidad del $\operatorname{poder}^{29}$. Porque si la seguridad de los gobernados se pone en peligro, ya no habría obligación de obedecer al Soberano ${ }^{30}$.

28 Como muy bien ha destacado A. de Julios, si en Hobbes no hay alugar alguno para la iva es el instrumento de la actuación indiscriminada del soberano, $\mathrm{y} \mathrm{cl}$ initivo para asegurar la obediencia del súbdito, el constructo hobbesiano pacto el argumento defía enfrentándose ante la constatación efectiva de su fracaso teóricom: A. de Julios Campuzano. La dincimica de la libertad. Sevilla: Universidad de Sevilla, 1997, p. 47.

29 Cf. Leviathan. Introducción

Sobre la esencial relación entre obediencia y protección, $c f$. Leviathan, «Repaso y conclusión», p. 713, [p. 547]]. Y en De Cive, VI, 3. [p. 57]. leemos: «Pues la seguridad es la razón de que los hombres se sometan a otros, y si ésta no se da, nadie entiende haberse sometido a otros ni haber perdido el derecho a defenderse por su cuenta. Porque ha de entenderse que nadie se obliga a nada ni renuncia a su derecho a todo sin que se haya provisto a su scguridad”. 
Al igual que ocurría con las leyes de naturaleza, que en un universo adveren obligarían in foro interno, mas no in foro externo, pues la vida misma estaría no hay para Hobbes ley injustativas, sin que por ello dejen de ser justas (pues es decir, si promueven justa) ${ }^{31}$, si no respetan las demandas de racionalidad,

perder legitimidad necesaria para ser obedecidas.
No otra es, pues, la leyes.32, acabarán por

aquello, importantísimo a nuestro juciobes cuando escribe, y no por azar, lo perdamos de vista, porque por juicio, de salus populi suprema lex ${ }^{33}$. Y no derse no sólo la conservación por salus populi, nos dice Hobbes, «debe entende lo posible, de la vida feliz de la vida de cualquier forma sino, en la medida agruparon voluntariamente en Estae esa fue la razón por la que los hombres se ces posible en la medida en que lo permituidos, para poder vivir lo más felicuencia, los que han aceptado la administración del poder humana. En conse-

31 «Ninguna ley puede ser injusta [...]. Sucede con las leyes del Estado lo mismo que con las reglas del juego: que lo que todos los jugadores acuerdan entre ellos, no es injusticia para
ningunon. Leviathan, XXX. p. 335, [p. 276]. Pero Hobbes distingue entre jusicia Así, en Diálogo entre un filósofo y un jurista leemos ebses distingue entre justicia y equidad. estatutaria, hecha por hombres, puede muy bien encontrarse iniquie apreciación: «En una ley Dialogue between a Philosopher and a Student encontrarse iniquidad pero no injusticia». A 25. IDicilogo entre un filósofo y un jurista, y escritos autobiográficos, ed Rodilla. Madrid: Tecnos, 1992, p. 24]. Y esto nos los dice exiográficos, ed. de Miguel Angel tiende por ambas cosas:»[...] injusticia es la transgresión explicando más adelante qué se entransgresión de una ley de la razón»: Ibid., pp. 25-26. porque la justicia no es algo anterior a la ley, 25-26. [p. 24]. Para Hobbes no hay ley injusta anterior a la justicia, por eso la ley es el criterio como si fuera un criterio para juzgarla: la ley es visto ya, que toda ley esté exenta de examen racional justo. Pero esto no significa, como hemos los dictados de la razón, estaría promoviendo la iniquidad, porque la ley, si no es de conformidad con XXX, p. 33. [p. 276]. Dicho con otras palabras, inuidad, y no sería una buena ley. Cf. Leviathan. significa que toda ley sea una buena ley, es decir, nue ley injusta para Hobbes, pero esto no equidad y el resto de los dictados racionales.

32 La política ha de perseguir el hien.

injustas, pues la ley es el criterio de lo justo (otra el mayor número. $Y$ si no puede haber leyes es un mandato de la razón, y, por consiguiente, que es que la ley no promueva la equidad, que al fracaso político), sí puede haber malas o que esté condenada, más tarde o más temprano. hacer buenas leyes. Pero ¿qué es una buena ley? Cuando digo ley justa, pues ninguna ley puede ser injusta. el bien del pueblo, $\mathrm{y}$, además, claro e inequívoco Una buena ley es aquello que es necesario para cuando va en beneficio del soberano, aunque no sea necesaria puede considerarse como buena lo es tal. Pues el bien del soberano y el bien del pueblocesaria para el pueblo; pero de hecho no que tiene súbditos débilesw: lbid XXXen del pueblo son inseparables. Es un soberano débil el

33 Cf. De Cive, XIII, 2, p. 112. 
se de Estados, obrarían contra la ley natural (al obrar contra la confianza depositada en ellos por los que les encargaron la administración del poder), si no se esforzasen todo lo que las leyes les permitan en que los ciudadanos estén provistos abundantemente de todos los bienes necesarios no sólo para la vida, sino para una vida placentera» ${ }^{34}$. Queda clara, así, la intención de Hobbes cuando esta salus populi es elevada al rango supremo, a la categoría de suprema lex 35 : elevar la política al horizonte de la racionalidad, lo cual significará que también el Soberano ha de "ponerse en el lugar de los gobernados» y promover políticas que permitan su bienestar y desarrollo.

Una vez más, pues, están los otros en el punto de mira hobbesiano. No hay política racional, por definición, si no cumple las demandas de las leyes de naturaleza, las demandas de la racionalidad; pero ocurre que, como vimos ya, y es preciso resaltarlo, Hobbes sintetiza la racionalidad de la conducta moral y política precisamente en la actitud empática, (privada o pública-salus populi) de ponerse en la piel del otro, y no sólo para no dañarle, sino, además, en el ámbito político, para proteger su vida y promover su autodesarrollo.

Por consiguiente, podríamos concluir que pese a lo que habitualmente se piensa de Hobbes, éste careció de una visión pesimista del ser humano, como también él mismo argumentó, pues el pesimismo le habría llevado, en su radicalización, es decir, si extraemos de él todas sus consecuencias, a considerar a aquél como un caso perdido. Y entonces sí que el hombre sería un lobo para el hombre. Pero Hobbes, sin ingenuidad, con realismo, pero con esperanza, creyó en la posibilidad de una salida humana para todos nuestros problemas.

Esa salida, lo hemos visto ya, es racional, y por tanto necesita del ámbito moral y político a un tiempo, pues implicará, al asumir la alteridad como elemento constitutivo de la racionalidad (sobrepasando, aunque sea por motivos egoístas, los estrechos límites del egoísmo miope) hacerse cargo del otro, tanto en el ámbito existencial-privado, como en el público, pues por lo que respecta a este último, quizás el más polémico, el Soberano que quiera seguirlo siendo, y al que debemos legítimamente obediencia, no podrá olvidar que la afirma-

34 Ibid., XIII, 2, 3, 4, [p. 113]. Puede verse también De Corpore Politico, or the Elements of Law. Moral and Politic, EW, Part II. IX. p. 220.

35 Y es que Hobbes tenía muy claros los compromisos asumidos tanto por el ciudadano (obediencia) como por el Soberano (protección). Buena prueba y síntesis de ello nos parece el siguiente texto: «¿Cuáles son esas leyes llamadas fundamentales? Pues no entiendo cómo una ley puede ser más fundamental que otra, con la sola excepción de la ley natural que nos obliga a todos a obedecer a aquél, quienquiera que fuere, a quien legítimamente y por nuestra propia seguridad hemos prometido obedecer; ni ninguna otra ley fundamental para un rey salvo la salus populi, la seguridad y bienestar de su pueblom: Behemoth, pp. 248-249, [Behemoth, ed. de Miguel Ángel Rodilla. Madrid: Tecnos, 1992, pp. 88-89]. 
ción «Salus populi suprema lex» (en la que los otros pasan a un primer plano) es según Hobbes, en lo que a la soberanía respecta, el principio político fundamental, por ser ese bienestar del pueblo la expresión más acabada de lo que para él es la racionalidad en el ámbito político, y, en consecuencia, la justificación última para una sociedad que aspira a ser racional, es decir, que se empeña en remover los obstáculos y establecer las condiciones jurídicas, políticas y materiales necesarias para que todos los individuos estén cada vez más cerca de su propio concepto de felicidad, lo cual sólo será posible si se empeña tenazmente en hacer de la justicia material y de la convivencia pacífica los pilares esenciales en los que cimentar la construcción de su política.

José Manuel Panea Márquez es profesor de Ética en la Universidad de Sevilla. Es autor de Querer la utopia. Razón y autoconservación en la Escuela de Frankfurt (Sevilla: Universidad de Sevilla, 1996), así como del Estudio preliminar y traducción a David Hume. De los prejuicios morales y otros ensayos (Madrid: Tecnos, 1998).

Dirección Postal: Facultad de Filosofía. Avda. San Francisco Javier s/n, 41005 Sevilla. 